\title{
openheart COVID-19 and its impact on the cardiovascular system
}

Saud Ahmed Khawaja (i) , ${ }^{1}$ Poornima Mohan, ${ }^{1}$ Richard Jabbour, ${ }^{1}$ Theodora Bampouri, ${ }^{1}$ Gemma Bowsher, ${ }^{1}$ Ahmed M M Hassan (1) , ${ }^{1}$ Farhan Huq, ${ }^{1}$ Lilit Baghdasaryan, ${ }^{1}$ Brian Wang, ${ }^{2}$ Amarjit Sethi, ${ }^{1}$ Sayan Sen, ${ }^{1}$ Ricardo Petraco, ${ }^{1}$ Neil Ruparelia, ${ }^{1}$ Sukhjinder Nijjer, ${ }^{1}$ Iqbal Malik, ${ }^{1}$ Rodney Foale, ${ }^{1}$ Michael Bellamy, Jaspal Kooner, ${ }^{1}$ Bushra Rana, ${ }^{1}$ Graham Cole, ${ }^{1}$ Nilesh Sutaria, ${ }^{1}$ Gajen Kanaganayagam, ${ }^{1}$ Petros Nihoyannopoulos, ${ }^{1}$ Kevin Fox, ${ }^{1}$ Carla Plymen, ${ }^{1}$ Punam Pabari, ${ }^{1}$ Luke Howard, ${ }^{1}$ Rachel Davies, ${ }^{1}$ Gulammehdi Haji, ${ }^{1}$ Francesco Lo Giudice, ${ }^{1}$ Prapa Kanagaratnam, ${ }^{1}$ Jon Anderson, ${ }^{3}$ Andrew Chukwuemeka, ${ }^{3}$ Ramzi Khamis, ${ }^{1}$ Amanda Varnava, ${ }^{1}$ Christopher S R Baker, ${ }^{1}$ Darrel Parthipan Francis, ${ }^{1}$ Perviz Asaria, ${ }^{1}$ Rasha Al-Lamee, ${ }^{1}$ Ghada W Mikhail ${ }^{1}$

\section{- Additional material is published online only. To view please visit the journal online (http://dx.doi.org/10.1136/ openhrt-2020-001472).}

To cite: Khawaja SA, Mohan P, Jabbour R, et al. COVID-19 and its impact on the cardiovascular system. Open Heart 2021;8:e001472. doi:10.1136/ openhrt-2020-001472

Received 3 0ctober 2020 Revised 23 December 2020 Accepted 22 February 2021
Check for updates

C) Author(s) (or their employer(s)) 2021. Re-use permitted under CC BY-NC. No commercial re-use. See rights and permissions. Published by BMJ.

${ }^{1}$ Cardiology, Imperial College Healthcare NHS Trust, London, UK

${ }^{2}$ Imperial College London,

London, UK

${ }^{3}$ Cardiothoracic Surgery, Imperial College Healthcare NHS Trust, London, UK

\section{Correspondence to}

Dr Ghada W Mikhail; g.mikhail@ imperial.ac.uk

\section{ABSTRACT}

Objectives The clinical impact of SARS-CoV-2 has varied across countries with varying cardiovascular manifestations. We review the cardiac presentations, in-hospital outcomes and development of cardiovascular complications in the initial cohort of SARS-CoV-2 positive patients at Imperial College Healthcare National Health Service Trust, UK.

Methods We retrospectively analysed 498 COVID-19 positive adult admissions to our institute from 7 March to 7 April 2020. Patient data were collected for baseline demographics, comorbidities and in-hospital outcomes, especially relating to cardiovascular intervention.

Results Mean age was $67.4 \pm 16.1$ years and $62.2 \%$ $(n=310)$ were male. $64.1 \%(n=319)$ of our cohort had underlying cardiovascular disease (CVD) with $53.4 \%$ $(n=266)$ having hypertension. $43.2 \%(n=215)$ developed acute myocardial injury. Mortality was significantly increased in those patients with myocardial injury (47.4\% vs $18.4 \%, p<0.001)$. Only four COVID-19 patients had invasive coronary angiography, two underwent percutaneous coronary intervention and one required a permanent pacemaker implantation. $7.0 \%(n=35)$ of patients had an inpatient echocardiogram. Acute myocardial injury (OR 2.39, 95\% Cl 1.31 to $4.40, p=0.005$ ) and history of hypertension (OR 1.88, 95\% $\mathrm{Cl} 1.01$ to 3.55 , $\mathrm{p}=0.049$ ) approximately doubled the odds of in-hospital mortality in patients admitted with COVID-19 after other variables had been controlled for.

Conclusion Hypertension, pre-existing CVD and acute myocardial injury were associated with increased inhospital mortality in our cohort of COVID-19 patients. However, only a low number of patients required invasive cardiac intervention.

\section{INTRODUCTION}

SARS-CoV-2 virus was first reported in Wuhan, China, in December 2019. It has

\section{Key questions}

What is already known about this subject?

- Initial data from China and the USA suggest involvement of cardiovascular comorbidities and myocardial injury being related to death in COVID-19 patients.

What does this study add?

- We aim to provide comprehensive data about COVID-19 and its cardiovascular impact on cardiovascular system in UK population. We aim to provide a detailed analysis of the impact of cardiovascular comorbidities in COVID-19 patients and the impact of myocardial injury. We also have provided a detailed analysis of cardiac intervention in this cohort of patients.

How might this impact on clinical practice?

- By identifying factors associated with increased mortality, we aim to risk stratify these patients. Also by identifying patients with myocardial injury, these patients may warrant increased cardiac team involvement. Furthermore, it aims to provide an insight into managing COVID-19 patients with cardiac issues in UK population.

since rapidly spread throughout the world and was declared a pandemic by WHO on 11 March 2020. ${ }^{1}$ There have been more than 17 million cases reported worldwide with 675000 deaths as of 30 July 2020. The UK has had over 300000 patients infected and more than 41000 deaths as of 30 July 2020.

Our understanding of COVID-19 remains limited, as the spread of the SARS-CoV-2 has been extremely rapid. Emerging data suggest that elderly patients and those with comorbidities have adverse prognosis, but the nature of the relationship between underlying 
cardiovascular disease (CVD), acute myocardial injury and COVID-19 outcomes remains unclear. ${ }^{2}$ Data from China suggest that acute myocardial injury in COVID-19 patients is associated with increased mortality. ${ }^{34}$ Infected patients have been reported to present with a wide range of cardiac issues from arrhythmias to ST elevation myocardial infarction (STEMI) mimics, excessive thrombus formation and fulminant myocarditis. ${ }^{5}$

This study describes a single centre experience of hospitalised COVID-19 patients from Imperial College Healthcare National Health Service (NHS) Trust, London, UK which comprises two receiving hospitals and one tertiary referral centre at the epicentre of the COVID-19 outbreak in the UK. We focus on the role of underlying cardiac disease and acute cardiac outcomes in these patients.

\section{METHODS}

\section{Study design}

We retrospectively analysed 498 consecutive patients with confirmed SARS-CoV-2 admitted to three central London hospitals forming Imperial College Healthcare NHS Trust, London, UK from 7 March 2020 to 7 April 2020. The trust is a cardiac tertiary referral centre for West London.

Patients with possible COVID-19 symptoms, who were sufficiently unwell to require admission to hospital were included if they had an initial positive nasopharyngeal swab by viral SARS-CoV-2 reverse transcription-PCR, or if they had a high pretest probability of COVID-19 and were confirmed positive on subsequent nasopharyngeal swab. Patients with high pretest probability of COVID-19 but without positive swabs were not included. Patients who became SARS-CoV-2 positive as a result of exposure in hospital having presented with alternative diagnoses, and those under the age of 18 years were excluded. All patients were followed until death, discharge or the end of the study period on 27 April 2020.

\section{Data collection}

Individual electronic medical records (Cerner) of patients were reviewed and relevant parameters were manually extracted onto a structured collection database. Patient data on baseline demographics, body mass index, SARS-CoV-2 confirmation, comorbidities and admission medications were recorded analysing individual case records. Comorbidities were further confirmed by manual review of relevant correspondence in health records, especially if they were not clearly stated in the patient's admission record. In-hospital course was reviewed, and data was collected on baseline heart rate, blood pressure, temperature and oxygen saturations on admission, requirement for respiratory support, echocardiographic parameters, initial and peak levels of prognostic biochemical markers, level of care required (intensive care vs ward based care) and in-hospital outcomes.

Myocardial injury was defined as a peak troponin greater than 99th percentile of the upper reference limit of high sensitivity troponin I (hs-TnI) (adjusted according to sex).

Pre-existing CVD was defined by the presence of hypertension, coronary artery disease (CAD)/ischaemic heart disease, valvular disease, impaired left ventricular (LV) function, arrhythmia, peripheral vascular disease or cerebrovascular disease. Patients were monitored for outcomes including death, discharge or continued inpatient treatment at the end of the monitoring period.

Patients or the public were not involved in the design, or conduct, or reporting, or dissemination plans of our research as it was a retrospective analysis and also to minimise interaction with COVID-19 patients.

\section{Statistical analysis}

The distributions of demographic characteristics, admission signs, pre-existing comorbidities, biomarkers (admission and peak) and the need for escalating levels of care were assessed for the whole cohort. These were then compared between those who died and those who remained alive at the end of the study using appropriate (parametric and non-parametric) tests of significance (see online supplemental table 5). Patients alive and continuing to require in-patient treatment were included in the alive group for baseline comparisons. Comorbidities were analysed separately for correlation with COVID-19 mortality, without combining into pre-existing comorbidity index such as the Charlson Score, as the relationship between COVID-19 and the separate elements of such risk scores is unknown. Logistic regression models were used to determine predictors of COVID-19 mortality. Patients continuing to require inpatient treatment at the end of the study were excluded from the regression modelling as their ultimate outcomes are unknown. In addition, variables which were poorly recorded (less than $80 \%$ completeness) were excluded as predictors. All analyses were carried out in SPSS V.24 and R V.3.6.3.

\section{RESULTS}

\section{Baseline Patient characteristics}

A total of 498 patients were admitted to Imperial College Healthcare NHS trust between 7 March 2020 and 7 April 2020 with COVID-19-related symptoms. The mean age of the cohort was $67.4 \pm 16.1$ years and 310 patients $(62.2 \%)$ were male (table 1$)$.

The most common comorbidities were hypertension $(53.4 \%)$, diabetes $(40.2 \%)$ and hyperlipidaemia $(31.7 \%) .13 .9 \%$ had a history of CAD, $6.6 \%$ had impaired LV function and $11.8 \%$ had a previous cerebrovascular accident. Chronic kidney disease (CKD) was seen in $19.7 \%$ of patients with $7.4 \%$ being on haemodialysis. The majority of patients were non-smokers $(91.8 \%)$, with 12 patients $(2.4 \%)$ and 29 patients $(5.8 \%)$ being previous and current smokers respectively (table 1 ).

On admission, 88 patients $(17.7 \%)$ were on aspirin and $58(11.6 \%)$ were anticoagulated. One hundred patients 


\begin{tabular}{|c|c|}
\hline Baseline demographics & $\begin{array}{l}\text { n (\%) } \\
(\mathrm{N}=498)\end{array}$ \\
\hline Age (years) & $67.4 \pm 16.1$ \\
\hline Male & $310(62.2)$ \\
\hline Weight $(\mathrm{kg})(\mathrm{n}=294)$ & $80.1 \pm 21.1$ \\
\hline BMI $\left(k g / m^{2}\right)(n=263)$ & $28.3 \pm 7.0$ \\
\hline \multicolumn{2}{|l|}{ Comorbidities } \\
\hline Hypertension & $266(53.4)$ \\
\hline Dyslipidaemia & $158(31.7)$ \\
\hline Diabetes & $200(40.2)$ \\
\hline Diet controlled & $40(20)$ \\
\hline Tablets & $103(51.5)$ \\
\hline Insulin & $57(28.5)$ \\
\hline COPD & $34(6.8)$ \\
\hline Asthma & $45(9.0)$ \\
\hline Chronic kidney disease & $98(19.7)$ \\
\hline ESRF on dialysis & $37(7.4)$ \\
\hline Coronary artery disease & $69(13.9)$ \\
\hline Previous MI & $45(9.0)$ \\
\hline Previous CABG & $11(2.2)$ \\
\hline Atrial fibrillation & $65(13.1)$ \\
\hline Previous PCl & $27(5.4)$ \\
\hline LV impairment & $33(6.6)$ \\
\hline Previous CVA & $59(11.8)$ \\
\hline \multicolumn{2}{|l|}{ Smoking status } \\
\hline Non & $457(91.8)$ \\
\hline Current & $12(2.4)$ \\
\hline Ex-smoker & $29(5.8)$ \\
\hline \multicolumn{2}{|l|}{ Admission medication } \\
\hline Aspirin & $88(17.7)$ \\
\hline Anticoagulation & $58(11.6)$ \\
\hline ACE Inhibitor & $100(20.1)$ \\
\hline Angiotensin receptor blocker & $52(10.4)$ \\
\hline Paracetamol & $95(19.1)$ \\
\hline NSAIDs & $10(2)$ \\
\hline Statin & $211(42.4)$ \\
\hline
\end{tabular}

BMI, body mass index; CABG, coronary artery bypass grafting; COPD, chronic obstructive pulmonary disease; CVA, cerebrovascular accident; ESRF, end-stage renal failure; LV, left ventricular; MI, myocardial infarction; NSAID, non-steroidal antiinflammatory drug; $\mathrm{PCl}$, percutaneous coronary intervention.

(20.1\%) were on an ACE inhibitor (ACEi) and 52 $(10.4 \%)$ on angiotensin receptor blockers (ARB).

\section{Mortality}

As of 27 April 2020, 462 patients (92.8\%) out of 498 had completed outcomes. One hundred and fifty-four patients $(30.9 \%)$ had died and 344 patients $(69.1 \%)$ remained alive, of which 36 patients $(10.5 \%)$ continued to require inpatient treatment.

The patients who died were older $(74.3 \pm 13.4$ years vs $64.1 \pm 16.2$ years, $\mathrm{p}<0.001)$ with higher respiratory rates $(25.9 \pm 11.3$ vs $24.0 \pm 8.8, \mathrm{p}=0.035)$ and lower oxygen saturations on air $(91 \%(87-96)$ vs $94 \%(89-96), p=0.019)$ at presentation than those who remained alive at the end of the study (table 2).

Patients with COVID-19 who died had higher incidence of pre-existing CVD ( $78.6 \%$ vs $57.6 \%, \mathrm{p}<0.001)$, CKD (27.3\% vs $16.3 \%, \mathrm{p}=0.05)$, diabetes $(46.8 \%$ vs $37.2 \%$, $\mathrm{p}=0.048)$, hypertension $(68.2 \%$ vs $46.8 \%, \mathrm{p}=0.001)$ and end-stage renal failure $(10.4 \%$ vs $6.1 \%, \mathrm{p}=0.099)$ compared with those who remained alive.

\section{Renin-angiotensin-aldosterone system blockade}

Use of ARB therapy was not significantly higher in those who died when compared with those who remained alive $(8.4 \%$ vs $11.3 \%, \mathrm{p}=0.428)$. In contrast, patients who died were more likely to be taking ACEi (26.6\% vs 17.2 $\%, \mathrm{p}=0.021$ ) .

\section{In-hospital outcomes}

In our patient cohort, 73 patients $(14.7 \%)$ were admitted to intensive care unit (ICU) and 58 patients $(11.6 \%)$ required intubation and ventilation. A total of 154 patients (30.9\%) died in-hospital due to COVID-19.

Patients who died more frequently had acute myocardial injury ( $66.2 \%$ vs $32.8 \%, \mathrm{p}<0.001)$, acute kidney injury (AKI) $(39.0 \%$ vs $16.0 \%, \mathrm{p}<0.001)$ and more commonly required renal replacement therapy $(8.4 \%$ vs $3.5 \%$, $\mathrm{p}=0.026)$ compared with those who remained alive. They were more frequently diagnosed with pneumonia $(77.3 \%$ vs $62.2 \%, \mathrm{p}=0.001$ ) (table 3).

\section{Blood parameters}

Admission and peak troponin levels, admission and peak d-dimer, B-type natriuretic peptide (BNP), C reactive protein (CRP) and creatinine were all significantly higher in patients who died in-hospital due to COVID-19 compared with those who were alive (table 4). Complete blood results are shown in online supplemental materials.

\section{Predictors of mortality}

Myocardial injury (OR 2.39, 95\% CI 1.31 to $4.40, \mathrm{p}=0.005$ ) and hypertension (OR $1.88,95 \%$ CI 1.01 to $3.55, \mathrm{p}=0.049$ ) emerged as significant predictors of in-hospital mortality in adjusted analyses, each approximately doubling the odds of mortality when compared with demographically similar patients without myocardial injury or hypertension. In contrast, use ACEi became a non-significant predictor $(\mathrm{p}=0.095)$ once hypertension was accounted for (online supplemental table 1).

\section{Myocardial injury}

A total of 215 patients had myocardial injury (43\%) based on their raised hs-TnI. The myocardial injury group has a higher proportion of patients with history of CVD ( $76.3 \%$ vs $54.8 \%, \mathrm{p}<0.001)$, hypertension $(64.2 \%$ 
Table 2 Mortality outcome based on baseline characteristics and presenting features

\begin{tabular}{|c|c|c|c|c|}
\hline & All $(\mathrm{N}=498)$ & Alive $(\mathrm{N}=344)$ & Dead $(\mathrm{N}=154)$ & $P$ value \\
\hline Age (years) & $67.4 \pm 16.1$ & $64.1 \pm 16.2$ & $74.3 \pm 13.4$ & $<0.001$ \\
\hline Male & $310(62.2 \%)$ & $206(59.9 \%)$ & $104(67.5 \%)$ & 0.11 \\
\hline Weight $(\mathrm{kg})(\mathrm{n}=294)$ & $80.1 \pm 21.1$ & $79.6 \pm 21.2$ & $81.2 \pm 20.9$ & 0.557 \\
\hline BMI $(n=263)$ & $28.3 \pm 7.0$ & $27.9 \pm 6.9$ & $29.2 \pm 7.1$ & 0.179 \\
\hline \multicolumn{5}{|l|}{ Comorbidities } \\
\hline Cardiovascular disease & $319(64.1 \%)$ & $198(57.6 \%)$ & $121(78.6 \%)$ & $<0.001$ \\
\hline Diabetes & $200(40.2 \%)$ & $128(37.2 \%)$ & $72(46.8 \%)$ & 0.048 \\
\hline Hypertension & $266(53.4 \%)$ & $161(46.8 \%)$ & $105(68.2 \%)$ & 0.001 \\
\hline Dyslipidaemia & $158(31.7 \%)$ & $100(29.1 \%)$ & $58(37.7 \%)$ & 0.061 \\
\hline COPD & $34(6.8 \%)$ & $20(5.8 \%)$ & $14(9.1 \%)$ & 0.183 \\
\hline Asthma & $45(9.0 \%)$ & $32(9.3 \%)$ & $13(8.4 \%)$ & 0.866 \\
\hline Chronic kidney disease & $98(19.7 \%)$ & $56(16.3 \%)$ & $42(27.3 \%)$ & 0.05 \\
\hline ESRF on dialysis & $37(7.4 \%)$ & $21(6.1 \%)$ & $16(10.4 \%)$ & 0.099 \\
\hline Coronary artery disease & $69(13.9 \%)$ & $40(11.6 \%)$ & $29(18.8 \%)$ & 0.036 \\
\hline Previous MI & $45(9.0 \%)$ & $25(7.3 \%)$ & $20(13.0 \%)$ & 0.044 \\
\hline Previous CABG & $11(2.2 \%)$ & $6(1.7 \%)$ & $5(3.2 \%)$ & 0.328 \\
\hline Atrial fibrillation & $65(13.1 \%)$ & $42(12.2 \%)$ & $23(14.9 \%)$ & 0.393 \\
\hline Previous PCl & $27(5.4 \%)$ & $15(4.4 \%)$ & $12(7.8 \%)$ & 0.135 \\
\hline Previous CVA & $59(11.8 \%)$ & $36(10.5 \%)$ & $23(14.9 \%)$ & 0.177 \\
\hline \multicolumn{5}{|l|}{ Medications } \\
\hline ACEi & $100(20.1 \%)$ & $59(17.2 \%)$ & $41(26.6 \%)$ & 0.021 \\
\hline ARB & $52(10.4 \%)$ & $39(11.3 \%)$ & $13(8.4 \%)$ & 0.428 \\
\hline NSAIDs & $10(2.0 \%)$ & $6(1.7 \%)$ & $4(2.6 \%)$ & 0.507 \\
\hline \multicolumn{5}{|c|}{ Observations on admission } \\
\hline Heart rate & $96.2 \pm 38.7$ & $96.0 \pm 44.3$ & $96.6 \pm 21.5$ & 0.87 \\
\hline Mean arterial pressure & $95.6 \pm 16.8$ & $95.5 \pm 15.3$ & $96.0 \pm 19.7$ & 0.781 \\
\hline Respiratory rate & $24.6 \pm 9.7$ & $24.0 \pm 8.8$ & $25.9 \pm 11.3$ & 0.035 \\
\hline Oxygen saturations & $94(88-96)$ & $94(89-96)$ & $91(87-96)$ & 0.019 \\
\hline
\end{tabular}

ACEi, ACE inhibitor; ARB, angiotensin receptor blocker; BMI, body mass index; CABG, coronary artery bypass grafting; COPD, chronic obstructive pulmonary disease; CVA, cerebrovascular accident; CVD, cardio-vascular disease; ESRF, end-stage renal failure; MI, Myocardial infarction; NSAID, non-steroidal anti-inflammatory drug; PCI, percutaneous coronary intervention.

vs $45.2 \%, \mathrm{p}<0.001)$, previous MI $(14.0 \%$ vs $5.3 \%, \mathrm{p}=0.001)$, atrial fibrillation $(19.1 \%$ vs $8.5 \%, \mathrm{p}=0.001)$ and of patients taking ARB ( $14.4 \%$ vs $7.4 \%, \mathrm{p}=0.017)$ (table 5). Patients with myocardial injury had higher probability of death $(47.4 \%$ vs $18.4 \%, \mathrm{p}<0.001)$.

\section{Cardiac intervention}

Two hundred and fifteen patients $(43.1 \%)$ had troponin elevation but only 11 patients $(2.2 \%)$ were diagnosed as having acute coronary syndrome (ACS) and 9 patients $(1.8 \%)$ were treated with dual antiplatelet therapy. Four patients were referred to our centres as STEMI patients with three of these cases taken to the cardiac catheter laboratory. Two of these STEMI cases needed percutaneous coronary intervention (PCI) (one following thrombolysis) and one had normal coronaries (online supplemental table 2).
One of the STEMI case presented was a 60-year-old man with severe COVID-19 respiratory disease and was intubated within hours of admission. Five days after admission, he developed anterior ST elevation with raised troponin and D-Dimer. The patient was felt to be too unwell for a transfer across site and PCI and he was treated with thrombolysis. The patient improved after thrombolysis but then redeveloped ST changes 1 week later. His echocardiogram showed moderate LV impairment with anterior regional wall motion abnormality. He was then transferred to Hammersmith Hospital and underwent primary PCI with drug-eluting stents from his left main stem to left anterior descending (LAD) (figure 1). The patient was stable postprocedure and transferred back to ICU. 
Table 3 In-hospital outcomes

\begin{tabular}{llllr}
\hline Outcomes & All (N=498) & Alive (N=344) & Dead (N=154) & P value \\
\hline Length of stay & $8(4-15)$ & $8(4-15)$ & $7(4-12)$ & 0.217 \\
\hline Admission to ICU & $73(14.7 \%)$ & $46(13.4 \%)$ & $27(17.5 \%)$ & 0.273 \\
$\quad$ Intubation & $58(79.5 \%)$ & $37(80.4 \%)$ & $21(77.8 \%)$ & 0.366 \\
\hline \multicolumn{1}{c}{ ICU stay (Days) } & $11.4 \pm 6.0$ & $12.35 \pm 6.4$ & $9.9 \pm 5.3$ & 0.105 \\
\hline Renal replacement therapy & $25(5.0 \%)$ & $12(3.5 \%)$ & $13(8.4 \%)$ & 0.026 \\
\hline Myocardial injury & $215(43.2 \%)$ & $113(32.8 \%)$ & $102(66.2 \%)$ & $<0.001$ \\
\hline Acute kidney injury & $115(23.1 \%)$ & $55(16.0 \%)$ & $60(39.0 \%)$ & $<0.001$ \\
\hline DIC & $3(0.6 \%)$ & $1(0.3 \%)$ & $2(1.3 \%)$ & 0.227 \\
Stroke & $8(1.6 \%)$ & $5(1.5 \%)$ & $3.0(1.9 \%)$ & 0.707 \\
\hline Pneumonia & $333(66.9 \%)$ & $214(62.2 \%)$ & $119(77.3 \%)$ & 0.001 \\
\hline
\end{tabular}

DIC, disseminated intravascular coagulation; ICU, intensive care unit.

Thirty-four patients $(6.8 \%)$ were reported to have inpatient arrhythmias with atrial fibrillation being the most frequent (online supplemental table 3). One patient was admitted with collapse and intermittent higher degree atrioventricular conduction block and required a permanent pacemaker. 35 patients $(7.0 \%)$ had an inpatient echocardiogram which were focused scans to minimise risk to the operator (online supplemental table 4) of which $51.4 \%$ (18 patients) had normal echocardiograms. Two patients were diagnosed with myocarditis. One had a normal coronary angiogram, with ECG changes and troponin rise. The second patient had severely impaired LV function on a background of known previous LV impairment but developed recurrent supraventricular arrythmia needing amiodarone. One patient had cardiac MRI (cMRI) which showed multiple small areas of late gadolinium enhancement (LGE) subendocardially, consistent with small infarcts but also some midwall oedema and LGE more suggestive of a myocarditic process (figure 2).

\section{DISCUSSION}

To our knowledge, this study represents the first case series of consecutive hospitalised confirmed COVID-19 patients in the UK describing cardiovascular outcomes. In-hospital mortality rate was $30.9 \%$ with $14.7 \%$ of patients being admitted to ICU. Our in-hospital mortality rate is comparable with published inpatient mortality of $28.2 \%$ in China and $21 \%-30 \%$ in the USA. ${ }^{267}$

We found that acute myocardial injury and history of hypertension significantly increased the odds of in-hospital mortality once other variables were accounted for.

\section{CVD and myocardial injury}

In our cohort, patients who died of COVID-19 had increased underlying CVD ( $78.6 \%$ vs $57.6 \%$ ). Hypertension was the most common cardiovascular comorbidity present in $53.4 \%$ of patients and significantly predicted outcome. A large report from Chinese Center for Disease Control and Prevention looking at outcomes in 44672 confirmed COVID-19 cases, reported overall mortality increasing from $2.3 \%$ to $10.5 \%$ in patients with CVD. ${ }^{8}$

Acute myocardial injury occurred in $43.2 \%$ of patients with raised hs-TnI levels. Patients who died from COVID-19 had higher rates of myocardial injury compared with those who survived $(66.2 \%$ vs $32.8 \%)$ regardless of underlying CVD status. Chinese data has shown the SARS-CoV-2 infection causes myocardial injury and is associated with worse outcomes. ${ }^{34}$ One cohort of 416 COVID-19 patients showed that $82(19.7 \%)$ patients had evidence of myocardial injury. Those with myocardial injury had a significantly higher associated in-hospital mortality (51.2\%),

\begin{tabular}{|c|c|c|c|c|}
\hline & All $(\mathrm{N}=498)$ & Alive $(\mathrm{N}=344)$ & Dead (N=154) & $P$ value \\
\hline CRP mg/L & $106(51-178)$ & $101(47-174)$ & $118(60-204)$ & 0.021 \\
\hline Troponin ng/L & $17(6-49)$ & $12(5-29)$ & $33(13-101)$ & $<0.001$ \\
\hline Peak Troponin ng/L & $20(7.5-85)$ & $14(6-48)$ & 55 (21-201) & $<0.001$ \\
\hline D-dimer $\mu \mathrm{g} / \mathrm{L}$ & 1403 (704-2764) & $1245(668-2338)$ & $1785(948-3447)$ & 0.004 \\
\hline Peak D-dimer $\mu \mathrm{g} / \mathrm{L}$ & 2223 (939-6481) & $1678(832-4756)$ & 3559 (1609-11157) & $<0.001$ \\
\hline Creatinine $\mu \mathrm{mol} / \mathrm{L}$ & 95 (72-142) & 89 (71-125) & $116(86-203)$ & $<0.001$ \\
\hline BNP ng/L & $38(13-142)$ & $28(11-87)$ & $90(20-343)$ & $<0.001$ \\
\hline
\end{tabular}

BNP, B-type natriuretic peptide; CRP, C reactive protein. 
Table 5 Comorbidities, medication and in-hospital outcomes according to myocardial injury

\begin{tabular}{|c|c|c|c|c|}
\hline & All $(\mathrm{N}=498)$ & Myocardial injury (N=215) & No myocardial injury ( $\mathrm{N}=\mathbf{2 8 3}$ ) & $P$ value \\
\hline \multicolumn{5}{|l|}{ Comorbidities } \\
\hline Cardiovascular disease & $319(64.1 \%)$ & $164(76.3 \%)$ & $155(54.8 \%)$ & $<0.001$ \\
\hline Diabetes & $200(40.2 \%)$ & $96(44.7 \%)$ & $104(36.7 \%)$ & 0.08 \\
\hline Hypertension & $266(53.4 \%)$ & 138 (64.2\%) & $128(45.2 \%)$ & $<0.001$ \\
\hline Dyslipidaemia & $158(31.7 \%)$ & $66(30.7 \%)$ & $92(32.5 \%)$ & 0.698 \\
\hline COPD & $34(6.8 \%)$ & $15(7.0 \%)$ & $19(6.7 \%)$ & 0.908 \\
\hline Asthma & $45(9.0 \%)$ & $18(8.4 \%)$ & $27(9.5 \%)$ & 0.753 \\
\hline Chronic Kidney Disease & 98 (19.7\%) & $73(34.0 \%)$ & $25(8.8 \%)$ & $<0.001$ \\
\hline ESRF on Dialysis & $37(7.4 \%)$ & $35(16.3 \%)$ & $2(0.7 \%)$ & $<0.001$ \\
\hline Coronary artery disease & $69(13.9 \%)$ & $40(18.6 \%)$ & $29(10.2 \%)$ & 0.009 \\
\hline Previous MI & $45(9.0 \%)$ & $30(14.0 \%)$ & $15(5.3 \%)$ & 0.001 \\
\hline Previous CABG & $11(2.2 \%)$ & $5(2.3 \%)$ & $6(2.1 \%)$ & 0.877 \\
\hline Atrial fibrillation & $65(13.1 \%)$ & $41(19.1 \%)$ & $24(8.5 \%)$ & 0.001 \\
\hline Previous PCl & $27(5.4 \%)$ & $17(7.9 \%)$ & $10(3.5 \%)$ & 0.044 \\
\hline Previous CVA & $59(11.8 \%)$ & $31(14.4 \%)$ & $28(9.9 \%)$ & 0.126 \\
\hline \multicolumn{5}{|l|}{ Medications } \\
\hline ARB & $52(10.4 \%)$ & $31(14.4 \%)$ & $21(7.4 \%)$ & 0.017 \\
\hline ACEi & $100(20.1 \%)$ & $52(24.2 \%)$ & $48(17.0 \%)$ & 0.055 \\
\hline \multicolumn{5}{|l|}{ Outcomes } \\
\hline Admission to ICU & $73(16.7 \%)$ & $40(18.6 \%)$ & $33(11.7 \%)$ & 0.04 \\
\hline Intubation & $58(11.6 \%)$ & $30(14.0 \%)$ & $28(9.9 \%)$ & 0.352 \\
\hline Renal replacement therapy & $25(5.0 \%)$ & $23(10.7 \%)$ & $2(0.7 \%)$ & $<0.001$ \\
\hline Stroke & $8(1.6 \%)$ & $4(1.9 \%)$ & $4(1.4 \%)$ & 0.731 \\
\hline Death & 154 (30.9\%) & $102(47.4 \%)$ & 52 (18.4\%) & $<0.001$ \\
\hline
\end{tabular}

ACEi, ACE inhibitor; ARB, angiotensin receptor blocker; CABG, coronary artery bypass grafting; COPD, chronic obstructive pulmonary disease; CVA, cerebrovascular accident; ESRF, end-stage renal failure; ICU, intensive care unit; MI, myocardial infarction; PCI, percutaneous coronary intervention.

compared with those without myocardial injury $(4.5 \%) .^{3}$ Guo et al reported 52 of 187 patients $(27.8 \%)$ had raised troponin $\mathrm{T}$ (TnT) levels. In-hospital mortality was $59.6 \%$ (31 of 52) in those with raised TnT compared with those with normal levels, $8.9 \%$ (12 of 135). ${ }^{4}$ We have seen similar increased mortality of $47.4 \%$ in those with myocardial injury compared with $18.4 \%$ in those with normal troponin levels. The highest mortality rates were

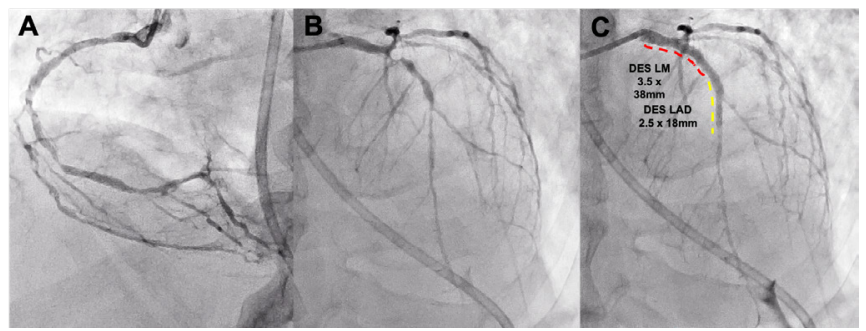

Figure 1 COVID-19 patient presenting with STEMI. Severe disease in RCA (A) and LAD (B). Treated with PCl from LMS to $L A D(C)$. LAD, left anterior descending; LMS, left main stem; $\mathrm{PCl}$, percutaneous coronary intervention; RCA, right coronary artery; STEMI, ST elevation myocardial infarction. observed in those who had underlying CVD and raised TnT levels $(69.4 \%)$.

\section{Mechanisms of cardiac injury and impact on cardiovascular system}

Patients with $\mathrm{CAD}$ and cardiovascular risk factors are at greater risk of cardiac events during acute infections and acute inflammatory conditions due to an increase in myocardial demand, causing myocardial injury or infarction in a type 2 myocardial infarction (MI) pattern. ${ }^{9-11}$ This is likely to be exacerbated by dehydration and acute kidney injury seen in many of the sickest patients in our cohort. Although severe inflammatory stress has been suggested to cause atherosclerotic plaque instability and rupture, we saw very little in the way of classical ACS or coronary artery plaque rupture in our patient cohort. Thromboembolic phenomena are thought to be associated with COVID-19 pathogenesis due to coagulopathy and endothelial dysfunction. This is reflected in raised troponin and D-Dimer levels. There have been suggestions that these may lead to coronary thromboembolism and present as ACS cases. ${ }^{12}$ In our cohort, only three 
Basal
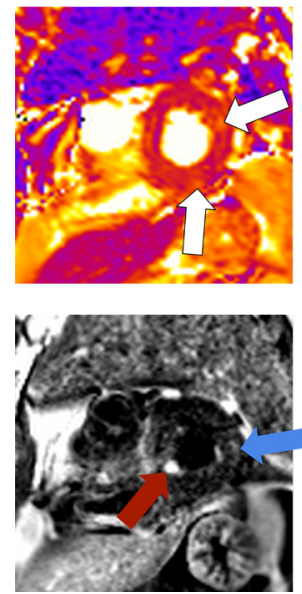

Mid
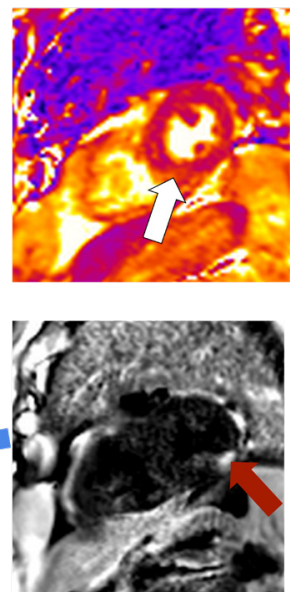

Apical
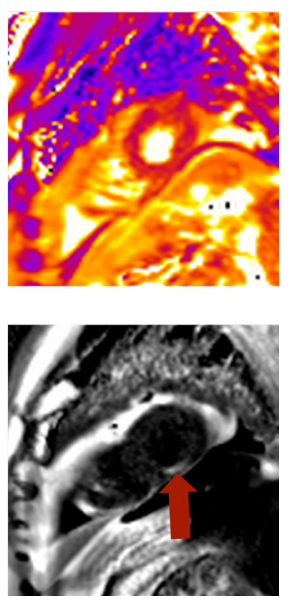

Figure 2 Cardiac MRI of a patient following a troponin rise during COVID-19 infection. The top row shows T2 maps, in which there are several areas of increased signal suggestive of recent myocardial injury (white arrows). The bottom row shows dark-blood late gadolinium enhancement images in which the myocardium should be dark grey. The three red arrows indicate separate areas of high signal which are multiple small myocardial infarctions in the basal inferoseptal, mid-inferolateral and apical inferior segments of the left ventricle. The blue arrow indicates subepicardial late gadolinium enhancement which may indicate a myocarditic process.

STEMI cases had invasive coronary angiography and none were felt to be related to this phenomenon. One had normal coronary arteries. The two other cases had diffuse CAD, likely related to underlying atherosclerotic disease than acute thrombotic COVID-19-related pathology. Their underlying atherosclerotic disease could have been exacerbated by their acute infection. Italian data have suggested that up to $40 \%$ of COVID-19 STEMI patients have no identifiable coronary culprit lesion to explain abnormal ECG and troponin rise. ${ }^{13}$

Thirty-four patients $(6.8 \%)$ were reported to have inpatient arrhythmias with atrial fibrillation being the most frequently observed rhythm, which is lower than the previously reported incidence of $16.7 \%$ by a Chinese group. ${ }^{14}$ As there appears to be no clear associated underlying ACS or LV dysfunction, these arrhythmias could be a consequence of severe underlying metabolic disturbances, hypoxia or severe inflammatory response.

Only 35 patients $(7.0 \%)$ underwent focused echocardiography during their admission. These were focused scans in order to minimise contact with patients and reduce exposure to staff. Eighteen $(51.4 \%)$ echocardiograms were normal (online supplemental table 3). Only four $(0.8 \%)$ patients had moderate-severe LV impairment in our cohort. Despite significant number of patients with myocardial injury, there were no corresponding echocardiographic changes observed, suggesting troponin rise more likely related to inflammatory response than direct involvement of the myocardium. A Chinese study similarly reported that cardiac involvement was secondary to systemic involvement as patients failed to show any typical echocardiographic or ECG changes of myocarditis ${ }^{15}$

Due to the respiratory deterioration, some patients have shown radiological findings that may be consistent with pulmonary oedema. However, despite these patients having raised cardiac biomarkers, we have not seen the development of acute LV failure on echocardiography. Despite patients having no echocardiographic ventricular impairment, BNP was significantly raised in patients who died. This possibly indicates myocardial dysfunction that contributes to overall mortality.

There has been one case report in the literature identifying marked biventricular diffuse LGE and interstitial oedema on cMRI, consistent with acute myocarditis. ${ }^{16}$ Our cMRI findings suggest that there may be multiple modalities of cardiac involvement in COVID-19 rather than typical myocarditis.

In hypertensive patients, there is a higher expression of ACE2 and it has been suggested that this is the mechanism which may increase their susceptibility to SARS-CoV-2 infection. However, there is lacking clear evidence linking any direct causation.

\section{ACEi and outcomes}

SARS-CoV belongs to the $\beta$-CoVs group and binds to the zinc peptidase ACE2, a surface molecule to enter the host cell. ${ }^{1718}$ Suppression of the ACE2 expression during SARS-CoV infection has been proposed to be involved in the pathogenesis of the disease in the lung, leading to severe infection and lung failure. ACEi/ARB can lead to increased upregulation of ACE2 receptors in the lungs which may contribute to lung pathology. Influenza A uses the same ACE2 receptor to mediate lung injury. A large UK analysis showed angiotensin blockade had no effect on influenza incidence or a lower incidence, depending on the duration of use. ${ }^{19}$ These observations for influenza may also apply to SARS-CoV-2. There are some suggestions that reninangiotensin-inhibitors (ACEi/ARBs) may have a theoretical benefit, but clinical data is lacking. ${ }^{20}{ }^{21}$ There have been concerns regarding the role renin-angiotensin-aldosterone system inhibitors have in COVID-19 patients. However, data from the USA, China and Italy have shown no association between ACEi/ARBs and COVID-19 mortality. ${ }^{22-25}$ Furthermore, there is at least one randomised control trial investigating the role of ACEi in COVID-19 (NCT04312009).

Although we found no mortality difference in patients on ACEi/ARB as a group, being on ACEi was linked to worse outcomes. Once this was adjusted for hypertension and myocardial injury, we found no increased mortality risk. However, we recognise our data represent a small patient group and current advice from international cardiology societies states that patients should remain on their medications until further definitive evidence is available. The role these medications play in the severity of lung disease is complex and not completely understood. 


\section{Cardiac management in COVID-19 patients}

The mainstay of COVID-19 management has been respiratory support, predominantly in the form of intubation and ventilation. ${ }^{24}$ There has been very limited success to date in identifying any antiviral drugs or vaccines to target SARS-CoV-2.

Patients with CVD are at greater risk of myocardial injury and adverse outcomes. Cardiac biomarkers should be performed on all patients admitted with COVID-19 routinely, particularly those with underlying CVD. Despite these patients needing limited cardiac intervention, the cardiovascular system is significantly associated with mortality in COVID-19 patients. Increased troponin levels may help identify high-risk patients and may lead to modification in treatment strategy.

Importantly, cardiac issues may be masked as patients who present with significant respiratory symptoms can deteriorate rapidly before cardiac issues become apparent.

There were initial concerns that infected patients may present with a varied range of cardiac complications, including STEMI, arrhythmias and cardiomyopathy. ${ }^{26}$ In our cohort of patients, despite in-hospital mortality being associated with underlying CVD and myocardial injury, we did not observe high numbers of patients requiring catheter laboratory procedures as initially expected. Despite the numbers requiring intervention being low, we need to be aware that these patients may have underlying cardiac disease that needs intervention without which their prognosis may be worse. The two cases that needed PCI in our cohort had severe underlying three vessel disease which required intervention.

Our low number of cardiology interventions is likely to reflect the need to minimise patient contact due to the highly infectious nature of SARS-CoV-2. More importantly, patients presenting in a critical clinical status would not have benefited from cardiac intervention. Many institutes like ours have written thrombolysis protocols for STEMIs in COVID-19 positive patients. In our cohort of patients, only one case was administered thrombolysis (online supplemental table 1). The long-term consequences of conservative management in such patients is unknown, and this will require long term follow-up to ascertain potential long-term sequelae.

\section{LIMITATIONS}

Our study includes only 498 patients in 3 centres within a single NHS institution and larger cohort studies are needed to verify our findings. Our study was also limited to the geographical and ethnic population of North West London. Our analysis was retrospective and was limited to reviewing electronic patient records. We were limited by incomplete datasets available for patients. Data are lacking on long-term consequences of cardiac injury. Long-term observational studies are, therefore, required to understand this further and to explore the effectiveness in managing such patients.

\section{CONCLUSION}

Our study demonstrates that pre-existing CVD and age predict worse outcomes in patients hospitalised with COVID-19. Furthermore, biochemical myocardial injury is associated with increased mortality. Fewer patients than expected required cardiac intervention. Further studies are needed to investigate the long-term cardiovascular outcomes of patients who have survived COVID-19.

\section{Twitter Saud Ahmed Khawaja @Saudakhawaja}

Acknowledgements The authors would like to thank Imperial College healthcare NHS Trust and Imperial College London for their support.

Contributors All authors have read and approved the manuscript. SAK, PM, RJ, $\mathrm{TB}, \mathrm{GB}, \mathrm{AMMH}, \mathrm{FH}, \mathrm{LB}$ and $\mathrm{BW}$ were responsible for planning and collecting data. AS, SS, RP, NR, SN, IM, RF, MB, JK, BR, GC, NS, GK, PN, KF, CP, PP, LH, RD, GH, FLG, $P K, J A, A C, R K, A V$ and CSRB were involved in writing of the manuscript. DPF, PA and $R A-L$ were involved in analysing the data. GWM was involved in all stages of the study. SAK and GMW are responsible for the overall content of the manuscript.

Funding The authors have not declared a specific grant for this research from any funding agency in the public, commercial or not-for-profit sectors.

Competing interests GWM is director of annual Imperial Valve and Cardiovascular Course (IVCC) which receives support from industry companies. She is also a director of an international fellowship supported by Abbott Vascular between Imperial Healthcare NHS trust, Villa Maria Cecilia Hospital GVM and Columbus Hospital Italy. RA-L has received speaker honorarium from Phillips Volcano.

Patient consent for publication Obtained.

Ethics approval Local ethical committee approval was obtained from the appropriate committees within Imperial College Healthcare NHS trust to carry out this retrospective COVID-19 data collection (CAR_036).

Provenance and peer review Not commissioned; externally peer reviewed.

Data availability statement Data are available on reasonable request. This will be deindentified participant data regarding COVID-19 patients admitted to Imperial College Healthcare NHS Trust. Data can be requested by contacting the corresponding author, GWM (g.mikhail@imperial.ac.uk).

Open access This is an open access article distributed in accordance with the Creative Commons Attribution Non Commercial (CC BY-NC 4.0) license, which permits others to distribute, remix, adapt, build upon this work non-commercially, and license their derivative works on different terms, provided the original work is properly cited, appropriate credit is given, any changes made indicated, and the use is non-commercial. See: http://creativecommons.org/licenses/by-nc/4.0/.

ORCID iDs

Saud Ahmed Khawaja http://orcid.org/0000-0001-5349-6087

Ahmed M M Hassan http://orcid.org/0000-0003-2532-918X

\section{REFERENCES}

1 World Health organisation, 2020. Available: https://www.who.int/dg/ speeches/detail/whodirector- general-s-opening-remarks-at-themedia-briefing-on-covid-19-11-march-2020

2 Richardson S, Hirsch JS, Narasimhan M, et al. Presenting characteristics, comorbidities, and outcomes among 5700 patients hospitalized with COVID-19 in the new York City area. JAMA 2020;323:2052.

3 Shi S, Qin M, Shen B, et al. Association of cardiac injury with mortality in hospitalized patients with COVID-19 in Wuhan, China. JAMA Cardiol 2020;5:802.

4 Guo T, Fan Y, Chen M, et al. Cardiovascular implications of fatal outcomes of patients with coronavirus disease 2019 (COVID-19). JAMA Cardiol 2020;5:811.

5 Mahmud E, Dauerman HL, Welt FGP, et al. Management of acute myocardial infarction during the COVID-19 pandemic: a consensus statement from the Society for Cardiovascular Angiography and Interventions (SCAI), the American College of Cardiology (ACC), and the American College of Emergency Physicians (ACEP). Catheter Cardiovasc Interv 2020;96:336-45.

6 Zhou F, Yu T, Du R, et al. Clinical course and risk factors for mortality of adult inpatients with COVID-19 in Wuhan, China: a retrospective cohort study. Lancet 2020;395:1054-62. 
7 Paranjpe I, Russak A, De FJK. Clinical characteristics of hospitalized Covid-19 patients in New York City. medRxiv 2020.

$8 \mathrm{Wu}$ Z, McGoogan JM. Characteristics of and important lessons from the coronavirus disease 2019 (COVID-19) outbreak in China. JAMA 2020;323:1239.

9 Madjid M, Miller CC, Zarubaev VV, et al. Influenza epidemics and acute respiratory disease activity are associated with a surge in autopsy-confirmed coronary heart disease death: results from 8 years of autopsies in 34,892 subjects. Eur Heart J 2007;28:1205-10.

10 Nguyen JL, Yang W, Ito K, et al. Seasonal influenza infections and cardiovascular disease mortality. JAMA Cardiol 2016;1:274-81.

11 Smeeth L, Thomas SL, Hall AJ, et al. Risk of myocardial infarction and stroke after acute infection or vaccination. $N$ Engl $J$ Med 2004;351:2611-8.

12 Lodigiani C, lapichino G, Carenzo L, et al. Venous and arterial thromboembolic complications in COVID-19 patients admitted to an academic hospital in Milan, Italy. Thromb Res 2020;191:9-14.

13 Stefanini GG, Montorfano M, Trabattoni D, et al. ST-elevation myocardial infarction in patients with COVID-19: clinical and angiographic outcomes. Circulation 2020;141:2113-6.

14 Wang D, Hu B, Hu C, et al. Clinical characteristics of 138 hospitalized patients with 2019 novel coronavirus-infected pneumonia in Wuhan, China. JAMA 2020;323:1061.

15 Deng Q, Hu B, Zhang Y, et al. Suspected myocardial injury in patients with COVID-19: evidence from front-line clinical observation in Wuhan, China. Int J Cardiol 2020;311:116-21.

16 Inciardi RM, Lupi L, Zaccone G, et al. Cardiac involvement in a patient with coronavirus disease 2019 (COVID-19). JAMA Cardiol 2020;5:819.
17 Hamming I, Timens W, Bulthuis MLC, et al. Tissue distribution of ACE2 protein, the functional receptor for SARS coronavirus. A first step in understanding SARS pathogenesis. J Pathol 2004;203:631-7.

$18 \mathrm{Li} \mathrm{F}$, Structure LF. Structure, function, and evolution of coronavirus spike proteins. Annu Rev Virol 2016;3:237-61.

19 Chung S-C, Providencia R, Sofat R. Association between angiotensin blockade and incidence of influenza in the United Kingdom. N Engl J Med 2020;383:397-400.

20 Imai Y, Kuba K, Rao S, et al. Angiotensin-converting enzyme 2 protects from severe acute lung failure. Nature 2005;436:112-6.

21 Rico-Mesa JS, White A, Anderson AS. Outcomes in patients with COVID-19 infection taking ACEI/ARB. Curr Cardiol Rep 2020;22:31.

22 Mancia G, Rea F, Ludergnani M, et al. Renin-AngiotensinAldosterone system blockers and the risk of Covid-19. N Engl J Med 2020;382:2431-40.

23 Reynolds HR, Adhikari S, Pulgarin C, et al. Renin-AngiotensinAldosterone system inhibitors and risk of Covid-19. N Engl J Med 2020;382:2441-8.

24 lingzhong M, Qiu H, Wan L. Intuabtion and ventilation amid the COVID-19 outbreak. Anesthesiology 2020.

$25 \mathrm{Li}$ J, Wang X, Chen J, et al. Association of renin-angiotensin system inhibitors with severity or risk of death in patients with hypertension hospitalized for coronavirus disease 2019 (COVID-19) infection in Wuhan, China. JAMA Cardiol 2020:5:825.

26 Kochi AN, Tagliari AP, Forleo GB, et al. Cardiac and arrhythmic complications in patients with COVID-19. J Cardiovasc Electrophysiol 2020;31:1003-8. 